\title{
Political discourse in the Internet space: subjects, forms, risks
}

\author{
Nikolay A.Volkov \\ Kemerovo State University \\ PhD (Philosophy), Associate \\ Professor of the Department of \\ Theory and History of State and \\ Law \\ Kemerovo, Russia) \\ ombudsman@mail.ru
}

\author{
Evgeny V. Golovatsky \\ Kemerovo State University \\ $\mathrm{PhD}$ in Sociological Sciences, \\ Associate Professor, Associate \\ Professor of the Department of \\ Sociological Sciences \\ Kemerovo, Russia \\ xomaik@rambler.ru
}

\author{
Larissa Y. Logunova \\ Kemerovo State University \\ Dr. of Sc. (Philosophy), \\ Associate professor, professor of \\ the Department of Sociological \\ Sciences \\ Kemerovo, Russia \\ vinsky888@mail.ru
}

\author{
Yaroslav M. Logunov \\ Kemerovo State University \\ Master of Sociology Department \\ of Sociological Sciences \\ Kemerovo, Russia \\ wind 01@mail.ru
}

\begin{abstract}
The Internet has turned into a space of mass communication. The network resources successfully compete with the media in formats and outreach to the audience. The study of political processes in the Internet space, the analysis of participating parties, the volume and the quality of network communications, and the models of discourse give a new direction to the sociological research - the sociology of the Internet. The transformation of social practices in the modern world justifiably brings changes in the traditional mechanisms of socio-political interaction. Political communications, which are in vanguard of actualization, articulation and demonstration of the socio-political relations, are exposed to the innovative processes and have to adapt to new challenges. New quantitative and qualitative characteristics of political communications, used in the Internet space, should be assessed outside the rigid good versus bad categories. The dynamic transformations of modern organizational and communication technologies cannot receive any prompt yet clear public assessment, and many aspects of political discourse are still at the stage of formation. Thus, it is crucial to explore the possibilities of social networks, the communicating parties, and the forms of communication and evaluate the potential of regular citizens (users) who are able to participate in the political discourse of the modern society.
\end{abstract}

Keywords - political communications; political discourse; Internet space; new class; social risks

\section{INTRODUCTION}

In times of turmoil, the Internet space becomes a platform for sharing news, eyewitness accounts, official statements, and discussions; hence it turns into an arena of political struggle and provides for the influence on electoral behavior. This outlines postmodern culture, which lets high technologies into the everyday life of all social strata rather than the elite only. Thus, the possibilities of political communications expand, but the danger of manipulating the mass consciousness of 'regular users' grows as well. Critical points of the public consciousness are not always triggered through information technologies in a noble and humane manner.
A feature of mass consciousness is an average level of understanding of the political processes and facts and the absence of reflection. A significant part of the Internet audience is sometimes unable to critically comprehend the intention behind the spread of information. Another part of this audience seeks to disorient the public consciousness (trolls). Finally, the third part of the audience uses the Internet space as a tool, giving no consideration to the axiological concepts and the normative content of communicative acts. All these users are a 'smart mob' (Rheingold). Despite being barely formed, the smart mob have already demonstrated new forms of protest and initiated self-destructive processes, provoking total surveillance that threatens freedom and aggravated the problem of ethics in political communications. This determines the risks of participation in the political discourse for the New Class (Gouldner) who are capable of reflection. Also, it influences the results of political discourse, the user behavior in the Internet space, and the communicative features of regular users. There appears a revolutionary opportunity to predict the effects and simulate the sustainable technologies of political discourse in the Internet space.

Institutions of state power show interest in using the Internet space and consider the possibilities of controlling it, by limiting it to intranet, blocking some Internet domains, or using agents of influence (for example, National Liberation Movement and Cossack Cyber-Squads in the Russianlanguage Internet). As a result, an Internet user may lose an independent stance in the political discourse and become subject to control. This contradicts the essence of the Internet space, which is marked by democracy and subjectivity. In the absence of common ground between the civil society, authorities, and Internet users, there arise a problem of hindering the political dialogue and a need to overcome filters and barriers to effective interaction. Such problems limit the possibilities of political communications and narrow down the variety of political discourse forms.

Discourse is a way of communicating and understanding the outside world, which manifests itself in speech acts of 
other people; a speech put in a communicative situation (Zellig Harris). It can also be regarded as a form of social behavior, a social practice in the public, cultural, historical and political contexts. By defining the discourse in terms of which or whose it can be, one can understand the communicative identity of the communicating party. Political discourse is determined by the peculiarities of political culture and the political activity of the participants of communication.

Having critically analyzed modern human communications, theorists of the Frankfurt School (Marcuse, Fromm, Habermas, Adorno, Horkheimer) criticized the moral and spiritual degradation of the contemporary society and described the modernity as a process of the self-destruction of enlightenment under the influence of technologies that manipulate public consciousness. The presented portrait of the postmodern era with its risks of developing social communications was rather controversial. A group of critically thinking intellectuals was declared a new agent of history. Horkheimer [1] believed that the task of the critical theory is to help the society form a truthful picture of the world. Habermas's project of Enlightenment of the public sphere was formulated to protect critical self-awareness, based on the principle of justice. Activity of an individual in free public associations in the forms of productive communicative practices was proclaimed essential to the public sphere. According to Habermas [2], the form of creative attitude to life is a dialogue, a free and open discussion, which manifests itself in the inter-subjective communicative practices of everyday life and reflects personal qualities and hidden spiritual needs of an individual.

Communication in the Internet space features interactivity. Also, it is similar to solidarity that people could manifest in certain social spheres [3]. The network capital (the skills of using the technological networks for one's own benefit) becomes significant in the mobile world alongside the monetary and social capital [4]. Rheingold summarized the social consequences of the dissemination of information and communication technologies and explained the social effect produced by their mass distribution; that is the formation of a 'smart mob' that changed the fundamentals of collective action. Teledemocracy is becoming a new form of political communication in the context of the information society with its new economy and new anthropology. The formation of a new politics can be witnessed now, and this politics must differ materially from the traditional liberal democracy, which is in conflict with the realities of the Internet age [5].

Modern humanities give a profound theoretical substantiation of the functioning of Internet space. Its existence was anticipated and described by Wiener and Capra; its structure was investigated by McQuail, Castells [6], Cooper [7], Bakhmin [8], and Parinov [9]; and communication practices and discourse-forming possibilities were studied by Rheingold, Poster, Kutyugin [10], and Dokuka [11]. The Internet audience and the influence of the Internet on contemporary Russian society were studied by Galitsky, Zalessky, Vershinin, Lepsky, and Bondarenko. McLuhan's concept of global village was followed by the theory of virtual society by Bühl. The Internet space as a phenomenon of contemporary culture was examined by Alexander, Ionin, Poster, Levi, Chernykh.

Studies of social processes in the Internet space have taken shape of a new discipline - the sociology of the Internet (Wellman, Ionin, Poster, Perrol, Filippov). The political discourse in the Internet space became possible due to a change in the social structure producing a new social group, referred to as 'New Class' (Gouldner) [12], 'creative class' (Florida) [13], and 'virtual class' (Kroker, Weinstein).

This paper aims to justify that the Internet is:

- a social space where the statuses of users (agents of discourse and political communications) are differentiated;

- a space of the political discourse organization;

- a space of political communication risks not only for an active user but for any participant of the network interaction.

\section{Materials And Methods (Model)}

This study addressed the forms and practices of political participation in the Internet, the mechanisms of user interaction (agitation, attack, interaction). The empirical data were obtained by the content analysis of political discourse (forums, blogs), the analysis of virtual discourse (sites of political communities). The methods, used to analyze the virtual discourse, helped to identify hidden qualitative content of the texts and latent meanings behind the messages.

\section{RESUlts AND DiscUSSION}

For the purposes of this study, the Internet is seen as a space limited by technological possibilities, filled with specific cultural norms and rules of user communication; a web of relationships in physical reality [14]. The metaphor 'World Wide Web' is used to refer to the access to information rather than to a technological network.

The Internet space has common features with the social space, which Bourdieu defined as a rationally structured and constructed diagram, a field of power interaction, and movements of various types of capital [15]. Filippov emphasizes the social origin of such space that the principle of distribution and correlation of social positions is projected upon [16]. The social space is filled with human corporeality and structured by status.

Similar to the social space, the Internet space is conceived, but unseen. Incorporating all the meanings of cyber-possibilities, multimedia, virtuality, democracy, decentralization, etc., it is an integral, active, autonomous environment, inhabited by man and consisting of technical, socio-cultural and social components. The Internet space, as an element of contemporary culture, includes the culture of technology, the culture of discourse, and the culture of usage. This is a socio-cultural space in form and a discourse space in essence. It is dialogic, technically organized, filled with information, and functioning in real time. The information environment of the Internet space directly impacts on the reality space. The Internet space gave shape to the user and service culture - cyberculture (technical, communicative, social). Such space creates opportunities for citizens to 
participate in the topical political issues of governance and to influence the authorities.

The Internet space is socially differentiated, playing the role of political agora for discussing events. Here, representatives of different social strata mix and encounter. Let us propose a metaphor 'big kitchen' that reflects the essence of political communication in the Internet space. Rooted in the social memory, this type of behavior presented passive resistance of the Soviet intelligentsia. People could only bring their accumulated discontent home to the kitchen that became an equivalent of Hyde Park and a platform of political discourse.

Under the conditions of decentralization and lack of regulation, the political discourse forms poorly coordinated information layers and structures of heterogeneous mainstream and looks like a mosaic of self-organized groups, agorae or public arenas. The center of political discourse is the agent who decides on the agenda. However, a user, incapable of reflecting political information, fails to distinguish between lies and truths or offer their own topics for discourse, and becomes prey to professional manipulators of public consciousness. The own agenda is unique and personalized, but it is doubtful that a lumpen is able to choose the agenda independently. This type of a user displays sporadic activity in the Internet space, and the consequences of such activity can be objectionable and even destructive.

A considerable part of ordinary people who do not have financial means or computer skills, remain outside the World Wide Web events. Thus, the Internet splits the society into two antagonistic layers: the virtual class and outsiders ("unskilled workers, marginal minorities, [...] groups at the lowest levels of the social ladder" [5, p. 291]). Ionin calls this state of things an 'information apartheid' [5], a term widely used by the media preaching the official ideology and imposing the political agenda.

The number of virtual class is the percentage of active voters in the society (in Russia, in 2015 it was $24 \%$ of the population, according to the Russian Public Opinion Research Centre). Ionin notes that this percentage includes the most educated and financially successful strata of the urban population, technointelligentsia, representatives of the scientific community, communication specialists - in the overwhelming majority, they are white men.

Taking residence in the Internet space, users retain social characteristics and differentiate by the social role. The criterion of differentiation, which makes political participation fundamentally measurable, is the intention: to know (the New Class), to lobby (the virtual political agents), to speak out (the convinced), to decide (the observers).

By analogy to maintaining stability in the societal systems that have a specific protective mechanism for compensation of losses, the virtual discourse participants have a resource potential, which can be accumulated from various sources (including remote and offline ones), and an ability to mobilize the 'scattered resources' of the Internet. The main advantage of the virtual discourse participants is the possibility of attracting additional resources from stable and unstable subsystems. The compensation mechanism can manifest itself in the redistribution of functional responsibilities of the discourse participants in order to temporarily replace the social subsystems that came out of the normal mode of operation or to obtain alternative opportunities.

The New Class are creative users, having university education and a specific kind of cultural capital - the brain capital. These users can create self-organizing virtual communities around online forums (chat rooms, messengers) based on common cultural codes. The core of this group is IT specialists who professionally operate in the Internet space with the purpose of actively influencing the political discourse. They can be grouped as follows: cyber-activists (for example, international network Anonymous, Russian hacking group Anonymous International), bloggers, political opposition communities in the social networks, university students. Exchanging links, they can organize successful actions to sabotage the reactionary politicians, use the Internet as an instrument of social mobilization or an information channel. Unlike bloggers who post regularly, these users speak out only in exceptional cases when they get fed up with something, although their presence online is tangible. The influence of opposition-minded intellectuals on the regular citizens seems exaggerated. However, their mobilization capabilities have a considerable potential. These users tend the 'big kitchen', without revealing themselves audibly and actively (refer to Table 1).

Creative activity destroys the traditional patterns of thinking and living and forms a specific way of reflecting and perceiving events. The creativity, which is inherent to the social nature of the New Class, is an act of disobedience. It is difficult to make such people obey. The social networks are heated with 'mute' discussions of topical political issues: there goes an active exchange of memes, photoshop images, political videos, etc. This is the specific format of rebel practices in the political discourse. But despite social, technological, intellectual, information resources, social organization, the New Class has little influence in the Internet space because this group lacks public support. Quantitatively, people who have a real opportunity to influence authorities through high technologies form less than $1 \%$ of the total number of Internet users. It is interesting to note Gouldner's new concept of the intellectual class united by the ideas of cultural capital and critical discourse (communicative and linguistic community) [17]. Gouldner includes engineers, managers, journalists, teachers, academic administrators, i.e. nearly everybody who received a university education, into the new intellectual class. Thus, the concept of intellectual class is gradually developing in the contemporary discourse. Creativity draws attention and public interest, but does not solve the vital tasks of the virtual users in real life.

Virtual political agents work for remuneration on political websites and hiring forums; they represent various social strata and groups that are active politically due to their life situations or convictions. This most numerous and active group in the political discourse is coordinated and managed from the outside and has a high degree of organization. Their 
main task is an attempt of the state control over the Internet space. Their political activity aims to counter the discourse of the New Class.

In the Russian-speaking Internet, the following groups with a rigid management structure are strenuous today:

- Virtual Front (participants of the Youth Parliament that are coordinated and managed by the State Duma),

- National Liberation Movement (lead by Yevgeny Fedorov, a deputy of the State Duma),

- Cossack Cyber-Squads (students of the Razumovsky Moscow State University of Technology and Management the First Cossack University);

- League of Secure Internet (founder of the league is Charitable Fund of St. Basil the Great, managed by Orthodox monarchist Konstantin Malofeev);

- Pro-government religious organizations that develop Internet monitoring projects (coordinated by the Russian Orthodox Church);

- Red Guards - organizations that romanticize denunciations (for example, WikiBlogger that created Who is who online lists of oppositionists who become targets of harassment, manhunt, arson; a possible leader is businessman Yevgeny Prigozhin).

These groups occupy a significant virtual territory in the Internet space (they operate on the extensive principle of reclaiming the information space) and play the role of propagandists and provocateurs in pursuit to protect the political positions of their coordinators. A heavy patriotic cudgel in hand, these users work in a straightforward manner and defend the views of the ruling party, descending to insults and juggling with facts. Their arguments are questionable and hardly prove anything. They often resort to the substitution of concepts and equivocation to take the discussion off the initial route and attack the opponent for casting any doubt on the current state policy (external or internal).

Hired trolls occupy a special place in this group. The trolling tactics is usually stealth. The research showed that bots regularly appear on forums, distributing information from Russian news agencies and pro-Kremlin bloggers. It is assumed that the offices of the 'trolling factories' are located in Moscow (Olgino District), and Saint Petersburg (Savushkina Street). RBC magazine published an investigation into the activities of this media holding (a probable investor is businessman Yevgeny Prigozhin). The Iranian authorities used similar tactics during the winter protests 2017-2018, flooding the social networks with bots to dissuade people from walking the streets in protest.

Trolls and bots are fairly easy to recognize by repeatedly replicated posts (the posts are identical regardless of the topic), spelling and punctuation mistakes, and emotional intensity of messages. They use insults rather than arguments through the lens of stereotyped image of the opponent. The posts and messages are usually very short because they have to work quickly and have no time to spear. The Iranian bots have fake accounts full of political slogans but showing no personal information. In average bots write $72-144$ posts a day, re-tweet a lot and create little original content. A bot network can be recognized by the fact that several accounts publish the same message almost simultaneously. Russian trolls also create fake accounts during the actions organized for a specific political situation. Members of the progovernment organizations can join such political actions and present a united front or change the role of agent for the role of troll. The preferred forms of political discourse are mobilization and provocative discursive practices.

In especially critical situations, official government structures may also join the discourse to exercise counterpropaganda or blocking. For example, in order to protect the Internet space in 2010 Iran created a 'cyberarmy' of well-paid professional hackers. Russian Federal Security Service, the Ministry of Internal Affairs, and the Ministry of Defence regularly monitor popular messaging channels. In October 2017 RBC reported that it is planned to launch a network of 100 anonymous political Telegram channels to form an agenda before the 2018 Presidential Election in Russia.

When a wave of discontent in the society turns into open protests, a battle begins in the virtual space with real life consequences. In January 2018 in Iran the virtual agents captured the protesters' faces on videos and photos in order to arrest these people later, while the protesters made a Twitter account, which posted the information on security officials, and reported bots and fake accounts that spread denunciations to the Twitter security team.

The convinced mostly represent the lower middle class, the lower working class, pensioners. Virtual rhetoric of the convinced is often very expressive. Standing in opposition to any reason and any speaker, they hate 'Gosdep' (the U.S. Department of State), 'kikes', gay people, fascists and enemies of Vladimir Putin. Their convictions are fanatical and cannot be rethought. Their posts are vast, thorough, categorical, but the arguments do not stand up to any criticism: it is superficial and banal. They often resort to the following method is used: they make a statement and give a link that the unconvinced opponent should click on and find a proof on the issue under discussion. The convinced categorized into the convinced fans of the Soviet rule, the convinced Orthodox believers, the convinced ones supporting any social issue without a specific political stance, etc.

The observers may come from any social strata and can represent working professions, pensioners, etc. Minions of morality, they form an unorganized category of rare guests in the 'big kitchen'. They can write long posts or like a lot, but they can hardly be persuaded or dissuaded as they practically ignore the efforts of virtual political agents to protect the Internet from historical negationism and the influence of the mythical 'fifth column' or 'political agents' from of different countries They use VK, exchange memes or read the new, concealing their political interests. In the discourse space the observers interact laconically; they can support a statement they liked but using graphical symbols only. Despite forming a voting majority, they avoid manifesting themselves in the political segment of the Internet space. In fact, they are the silent mob for whose consciousness the virtual political agents 
are fighting for. It should be noted that in many respects the text messages used in computer and mobile communications are no different to the slang of social groups: without realizing it, the speakers tend to directly communicate in the way that members of their group do [18].

\section{TABLE 1. VIRTUAL DISCOURSE OF POLITICAL PARTICIPATION IN THE INTERNET SPACE}

(results of the content analysis of 5 forums and 14 sites in September 2016 through March 2017 )

\begin{tabular}{|l|l|l|}
\hline \multirow{2}{*}{ User category } & \multicolumn{2}{|c|}{ Structure of discourse } \\
\cline { 2 - 3 } New Class & $\begin{array}{l}\text { Indicative attributes } \\
\text { Self-organizing } \\
\text { communities, less than } \\
1 \% \text { of active users, } \\
\text { IT specialists, creative } \\
\text { intellectuals, professors, } \\
\text { teachers }\end{array}$ & $\begin{array}{l}\text { Dogically structured } \\
\text { statements: thesis - } \\
\text { argument, regular } \\
\text { blogging, netiquette, } \\
\text { grammatically correct } \\
\text { language. }\end{array}$ \\
\hline \multirow{5}{*}{$\begin{array}{l}\text { Virtual Political } \\
\text { Agents }\end{array}$} & $\begin{array}{l}\text { Manageable students, } \\
\text { small businessmen, } \\
\text { marginalized people in } \\
\text { need of money }\end{array}$ & $\begin{array}{l}\text { Replicated posts, poor } \\
\text { language with spelling } \\
\text { mistakes, breach of } \\
\text { netiquette, fake accounts, } \\
\text { posts with expressive } \\
\text { offensive content. }\end{array}$ \\
\hline Convinced Ones & $\begin{array}{l}\text { Pensioners, Soviet rule } \\
\text { fans, retired military } \\
\text { men, unemployed people }\end{array}$ & $\begin{array}{l}\text { Long posts, use of external } \\
\text { links as arguments; often } \\
\text { repost 'long-wandering' } \\
\text { materials in the Internet. }\end{array}$ \\
\hline \multirow{2}{*}{ Observes } & $\begin{array}{l}\text { Working young people, } \\
\text { skilled workers, middle- } \\
\text { aged people }\end{array}$ & $\begin{array}{l}\text { Graphic expressive means } \\
\text { smiles, memes, short } \\
\text { answers, quotes and } \\
\text { reposts from the official } \\
\text { media. }\end{array}$ \\
\hline
\end{tabular}

A group that stands aside is the new Luddites. Unlike the equipped mob who use new technologies for their benefit and success in the society, the new Luddites seen to be more pessimistic, cynical and isolated. Despite rejection of the Internet communications as a mainstream interaction channel, representative of this category certainly have political interests and relations [19].

The observers are the most numerous yet the most vulnerable group in terms of the communicative impact, as they possess insufficient knowledge to reflect on and resist to the political manipulations.

\section{CONCLUSION}

It can be said that socio-political conflicts have moved from the struggle for territory to the struggle for control over public consciousness. The political segment of the Internet space consists of user enclaves, postulating their own opinion, poorly related to the opinion of a partner or an opponent. The Internet communications is one of the areas of virtual discourse analysis. The authorities actively seek to manage the political discourse and determine the agenda. For example, the elites in power may seek to define the time, the virtual place and the purpose of participation in a communicative event by one or another agent of communication. The management of public discourse is, in essence, the management of the consciousness of the virtual audience.
The political discourse in the Internet space has the following attributes: dynamism, procedurality, personification, contextuality, socio-cultural markedness. Simultaneous communication of several users from anywhere on the Earth blurs the national, economic, and political boundaries. However, the cultural boundaries remain almost unchanged and can serve for differentiating the Internet users. The socially differentiating attributes become indicators helping to recognize the participants of the political discourse. The young generation of 'Pokemon catchers' provides the most active semantic basis for discussion. This newly born political agent is poorly studied yet; however, it is already able to communicate using new technologies, innovative practices and organizational forms of the political discourse.

The research led us to the conclusion that the New Class operates in a creative intensity format, occupies niches and spaces unknown to the virtual political agents who lack technological expertise and rely on protection from their coordinators. The virtual political agents operate extensively, usually by frontal attack, consuming many resources, which are often difficult to replete, attracting significant human resources, producing too many posts and 'online trash'. The New Class chooses focused influence on the political discourse in the original forms of the specified subcultural groups (cyberpunks hackers, web designers, etc.).

In the international practice of organizing political discourse, the social networks demonstrated unique organizational capabilities and brilliantly fulfilled the task of mobilizing and uniting people (New York, London, Cairo, Moscow). Thanks to the invisible thread linking the participants, there appears an alternative reality featuring genuine equality. However, a solution of the organizational task cannot substantiate an idea of new world order. The Internet-based smart mob helped the protesters to bring people to the streets during the Arab spring, Occupy Wall Street to draw attention to the irresponsibility of aggressive banking policies, Telegram users to organize protests in Iran, but it failed to formulate an alternative socio-political platform. It happened to be a protest for the sake of protest.

The 2017 protests in Russia overturned the official hypothesis on stability, inertia, and predictability of the political situation, which seemed to easily foreseeable for more than a year ahead. This urged the society to discuss the prohibitory laws with a view to restrict access to a number of network resources and increase the state control over the Internet space. It was recognized that the virtual space mirrors the alignment of political forces and that the real life political processes have a virtual superstructure. This space can be a specific resource for developing the forms of political interaction between the users and the government in a democratic civil society. However, if the government gets carried away by the idea of control and management of the information flows in the space that values free access to information most, more political protests of the oppositionminded citizens can be expected. This contradiction adds tension to the content and saturation of the political discourse in the Russian-speaking Internet space. 


\section{REFERENCES}

[1] M. Horkheimer, "Eclipse of Reason", Transl. German, M.: Canon +, 2011.

[2] J. Habermas, "Moral consciousness and communicative action", Transl. German, St. Petersburg: Science, 2001.

[3] J. Habermas, "Involving another. Essays on Political Theory", Transl. German, St. Petersburg: Science, 2001

[4] H. Rheingold, "Smart Mobs: The Next Social Revolution", Transl. English, M.: Fair Press, 2006.

[5] L.G. Ionin, "Sociology in the Knowledge Society: From the Modern Age to the Information Society", Moscow: Izd. House of the Higher School of Economics, 2007. P. 167.

[6] M. Castells, "The Internet Galaxy: Reflections on the Internet, Business and Society", Ekaterinburg, 2004.

[7] I. R. Cooper, "Hypertext as a form of organization of social knowledge" Sociological journal, vol. 1/2, 2000, URL: http://www.nir.ru/Socio/scipubl/socjour.htm.

[8] A. V. Bakhmin, "Cooperation and Conflict in the Virtual Community", Sociological Journal, vol. 1, 1997, pp. 65-92.

[9] S. I. Parinov, "Online communities: research methods and practical construction", Novosibirsk, 2000.
[10] D. I. Kutyugin, "Internet as the communicative space of the information society", Moscow: Moscow State University, 2009.

[11] S. V. Dokuka, "The practice of using online social networks" Sociological research, vol. 1, 2014, pp. 137-145.

[12] A. Gouldner, "The oncoming crisis of Western sociology", SaintPetersburg, 2003.

[13] R. Florida, "Creative Class: People Who Create the Future", Transl. English, Moscow: Mann, Ivanov i Ferber Publ., 2016.

[14] F. Capra, "The Web of Life. New scientific understanding of living systems", Transl. English, Moscow: Sofia, 2003.

[15] P. Bourdieu, "Sociology of Social Space", Transl. French, M.: Institute of Experimental Sociology; St. Petersburg: Aleteya, 2007.

[16] A. F. Filippov, "Sociology of space", Saint-Petersbur: Vladimir Dahl, 2008.

[17] A. W. Gouldner, "The future of intellectuals and the rise of the new class", N. Y.: Seabury-press, 1979, P. 128.

[18] K. Tracy, J. Robles, "Everyday Talk: Structure and Reflection of Identity", Transl. English, Kharkov: Publishing house "Humanitarian Center", 2015.

[19] Penn M.J., Zalesn K. E. "Microtendencies: Small changes leading to large changes", Transl. English, Moscow: AST: AST MOSCOW, 2009. 